\title{
Correction to: Cyr61 synthesis is induced by interleukin- 6 and promotes migration and invasion of fibroblast-like synoviocytes in rheumatoid arthritis
}

Changmin Choi ${ }^{1}$, Wooseong Jeong ${ }^{2}$, Byeongzu Ghang ${ }^{2}$, Yonggeun Park ${ }^{3}$, Changlim Hyun ${ }^{4}$, Moonjae Cho ${ }^{5^{*}}$ and Jinseok Kim ${ }^{*}$

Correction to: Arthritis Res Ther 22, 275 (2020)

https://doi.org/10.1186/s13075-020-02369-8

Following publication of the original article [1], a typesetting error occurred in the spacing of text in Figs. 1a, d, f, Fig. 3f, Fig. 4a-c, e, f, Fig. 5a and f.

The corrected figures are given in this correction article. The original article [1] has been corrected.

\begin{abstract}
Author details
'Department of Medicine, Jeju National University School of Medicine, Jeju, Republic of Korea. ${ }^{2}$ Division of Rheumatology, Department of Internal Medicine, Jeju National University Hospital, Aran 13gil, Jeju 690-797, Republic of Korea. ${ }^{3}$ Department of Orthopaedic Surgery, Jeju National University Hospital, Jeju, Republic of Korea. ${ }^{4}$ Department of Pathology, Jeju National University Hospital, Jeju, Republic of Korea. ${ }^{5}$ Department of Biochemistry, Jeju National University School of Medicine, Aran 13gil, Jeju 690-797, Republic of
\end{abstract} Korea.

Published online: 15 December 2020

\section{Reference}

1. Choi C, Jeong W, Ghang B, et al. Cyr61 synthesis is induced by interleukin-6 and promotes migration and invasion of fibroblast-like synoviocytes in rheumatoid arthritis. Arthritis Res Ther. 2020;22:275 https://doi.org/10.1186/ s13075-020-02369-8.

* Correspondence: moonjcho@jejunu.ac.kr; slera@yahoo.com

${ }^{5}$ Department of Biochemistry, Jeju National University School of Medicine, Aran 13gil, Jeju 690-797, Republic of Korea

2Division of Rheumatology, Department of Internal Medicine, Jeju National University Hospital, Aran 13gil, Jeju 690-797, Republic of Korea

Full list of author information is available at the end of the article

(c) The Author(s). 2020 Open Access This article is licensed under a Creative Commons Attribution 4.0 International License, which permits use, sharing, adaptation, distribution and reproduction in any medium or format, as long as you give appropriate credit to the original author(s) and the source, provide a link to the Creative Commons licence, and indicate if changes were made. The images or other third party material in this article are included in the article's Creative Commons licence, unless indicated otherwise in a credit line to the material. If material is not included in the article's Creative Commons licence and your intended use is not permitted by statutory regulation or exceeds the permitted use, you will need to obtain permission directly from the copyright holder. To view a copy of this licence, visit http://creativecommons.org/licenses/by/4.0/ The Creative Commons Public Domain Dedication waiver (http://creativecommons.org/publicdomain/zero/1.0/) applies to the data made available in this article, unless otherwise stated in a credit line to the data. 
A.

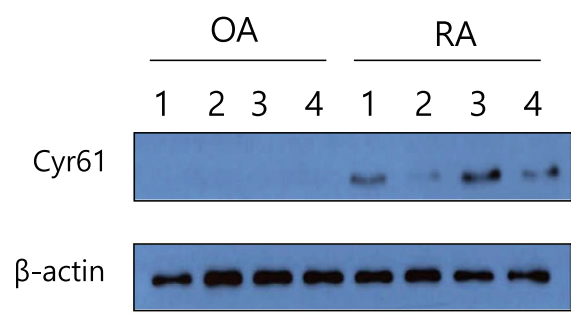

C.
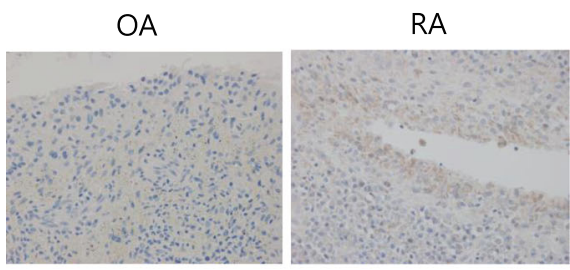

Cyr61

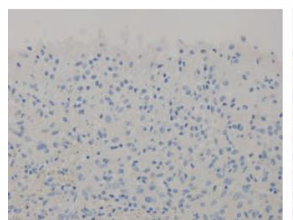

D.

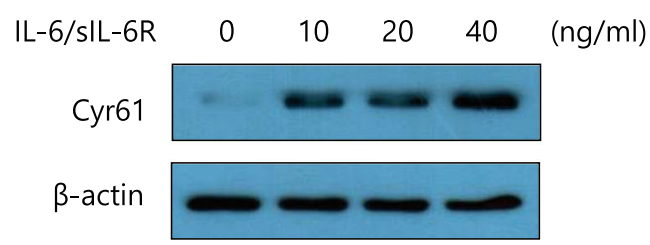

F.

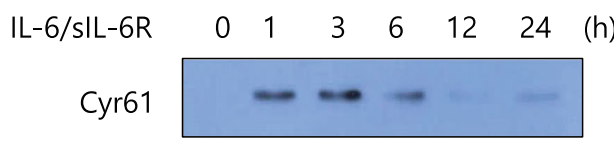

$\beta$-actin

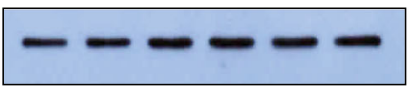

IL-6

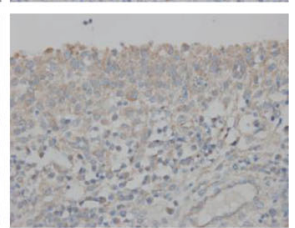

B.

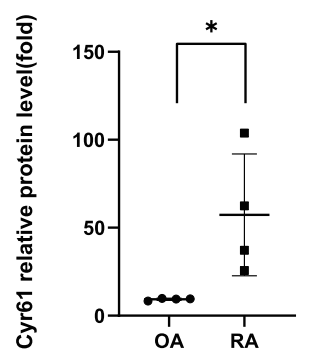

E.

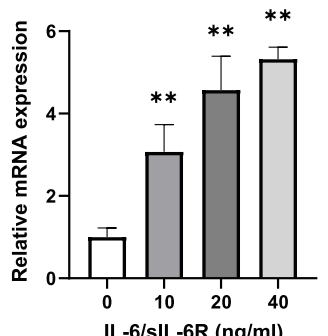

G.

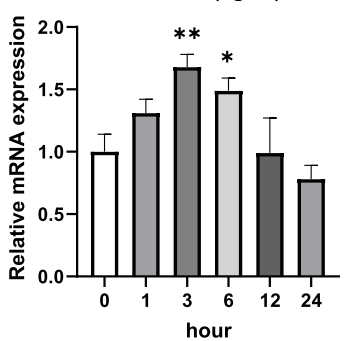

Fig. 1 Expression of IL-6 and Cyr61 in fibroblast-like synoviocytes (FLSs). a, b FLSs from osteoarthritis (OA; $n=4)$ or rheumatoid arthritis (RA, $n=4)$ patients. ${ }^{*} p<0.05$ vs OA. c Synovial tissues from OA or RA patients. Original magnification $\times 400$. d, e RA FLSs stimulated by IL-6/sIL-6R for $2 \mathrm{~h}$. f, g FLSs stimulated by $\mathrm{IL}-6 / \mathrm{s} \mathrm{IL}-6 \mathrm{R}(20 \mathrm{ng} / \mathrm{mL})$ for the indicated periods. $\mathbf{d}-\mathbf{g}$ FLSs were incubated overnight in $1 \%$ FBS-containing medium before treatment with IL-6/SIL-6R. $\mathbf{a}, \mathbf{b}, \mathbf{d}$, f Protein levels were determined by western blotting. $\mathbf{e}, \mathbf{g}$ The mRNA levels of Cyr61 were determined through real time polymerase chain reaction. Values are means ( \pm standard deviation) of at least three independent experiments. ${ }^{*} p<0.05$, ${ }^{* *} p<0.01$ vs untreated cells. IL-6, interleukin-6; sIL-6R, soluble IL-6 receptor; FBS, foetal bovine serum 
A.

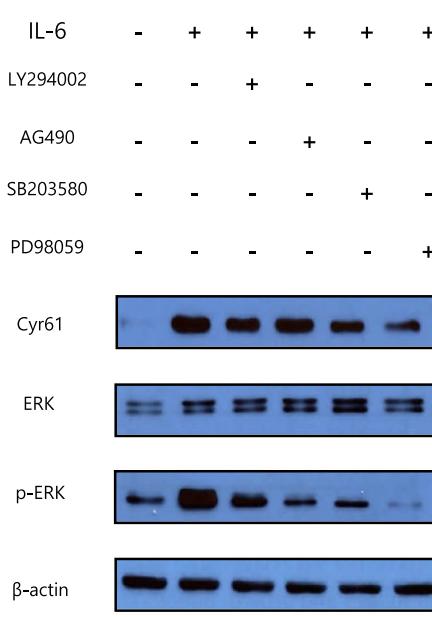

D.

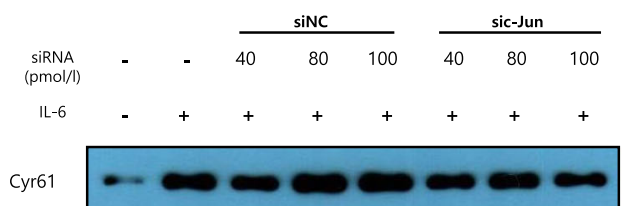

c-Jun

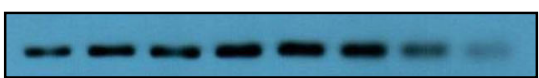

$\beta$-actin

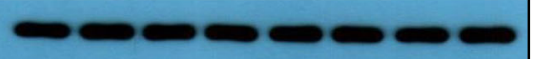

C.

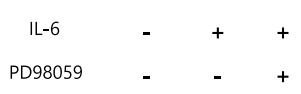

Cyr61

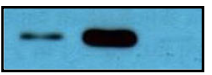

c-Jun

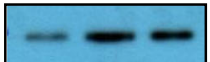

ERK

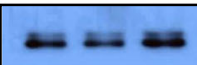

p-ERK

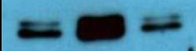

$\beta$-actin

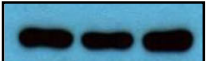

E.

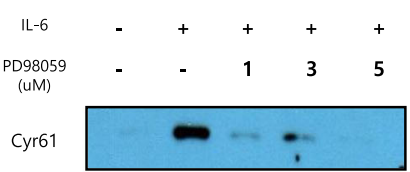

EGR3

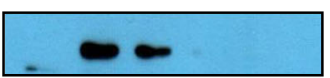

$\beta$-actin

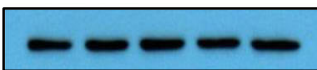

F.

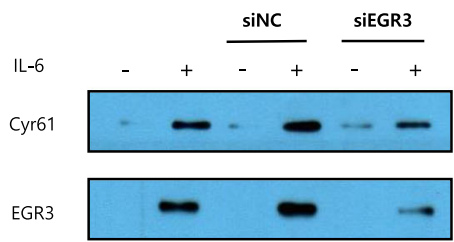

$\beta$-actin

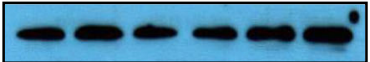

Fig. 3 Signalling pathways involved in IL-6-regulated protein synthesis of Cyr61 in rheumatoid arthritis-fibroblast-like synoviocytes (RA-FLSs). a, c,

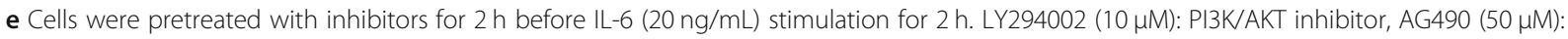

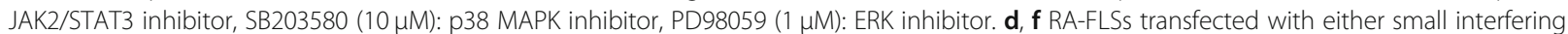
RNA (c-Jun or EGR3) or siNC (control) $(20 \mathrm{pmol} / \mathrm{L})$ stimulated by $\mathrm{IL}-6(20 \mathrm{ng} / \mathrm{mL})$ for $2 \mathrm{~h}$. Data are representative of at least three independent experiments. a-f Protein levels were determined by western blotting. FLSs were incubated overnight in $1 \%$ FBS-containing medium before treatment with $I L-6 / s \mid L-6 R$ 
A.
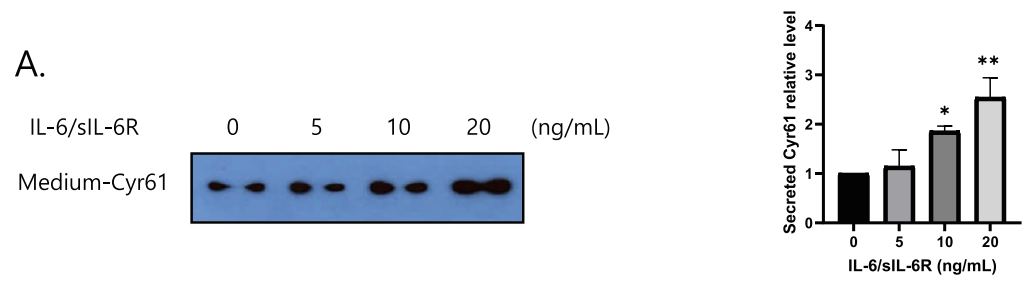

B.
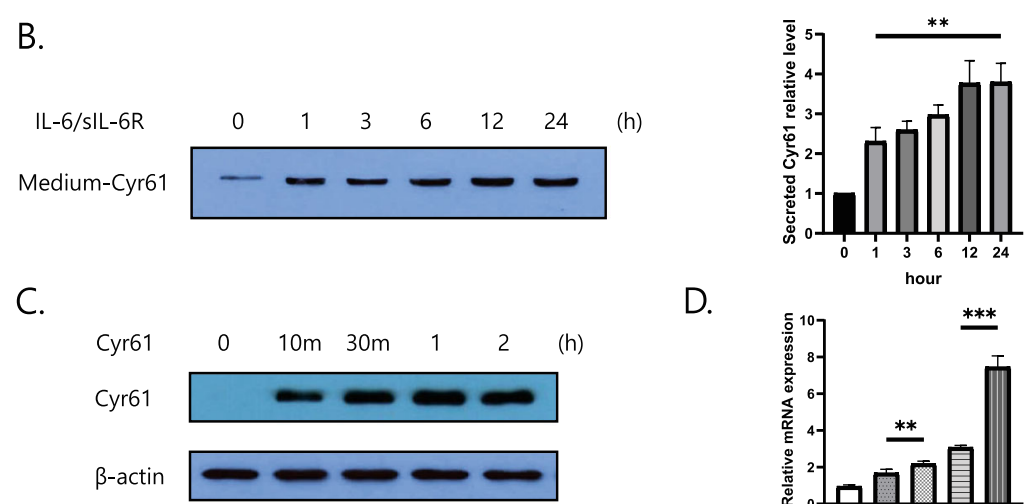

D.

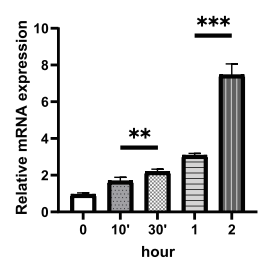

E.

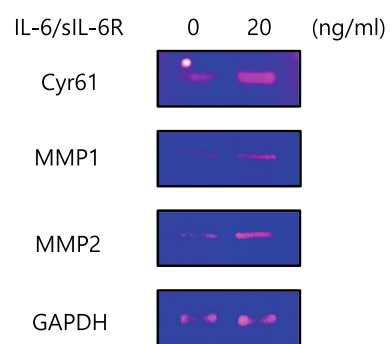

F.

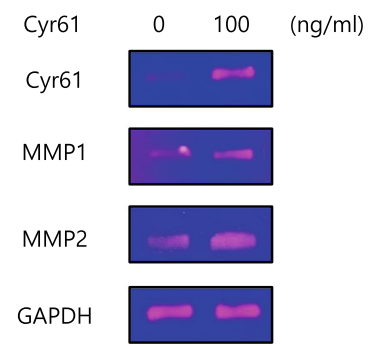

G.

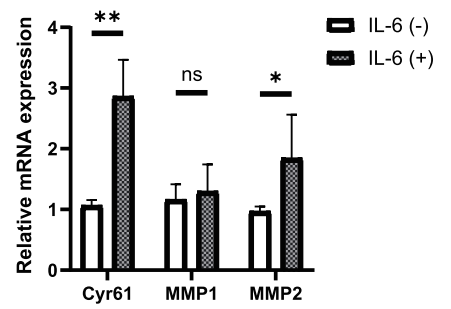

$\mathrm{H}$.

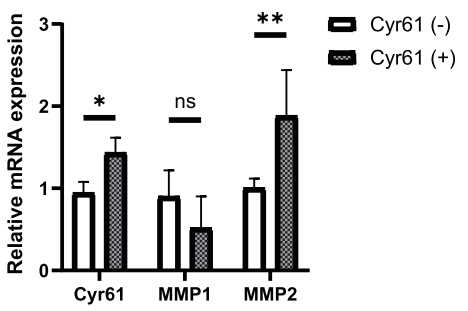

Fig. 4 Cyr61 secretion induced by IL-6. a, b Extracellular protein levels of Cyr61 in culture supernatants of IL-6-treated RA-FLSs measured by western blotting. b IL-6 (20 ng/mL). c, d FLSs stimulated by extracellular Cyr61 $(100 \mathrm{ng} / \mathrm{mL})$ for indicated time periods. c Protein levels were determined by western blotting. $\mathbf{d}$ The mRNA levels of Cyr61 were determined through real time polymerase chain reaction. $\mathbf{e}-\mathbf{h}$ The mRNA levels of Cyr61, MMP1, 2, and GAPDH induced by IL-6 $(20 \mathrm{ng} / \mathrm{mL})$ and extracellular Cyr61 protein $(100 \mathrm{ng} / \mathrm{mL})$ for $2 \mathrm{~h}$. e, f The mRNA levels were determined by reverse-transcription polymerase chain reaction. $\mathbf{g}, \mathbf{h}$ The mRNA levels were determined through real time polymerase chain reaction. Data are representative of at least three independent experiments. ${ }^{*} p<0.05,{ }^{* *} p<0.01,{ }^{* * *} p<0.001$ 


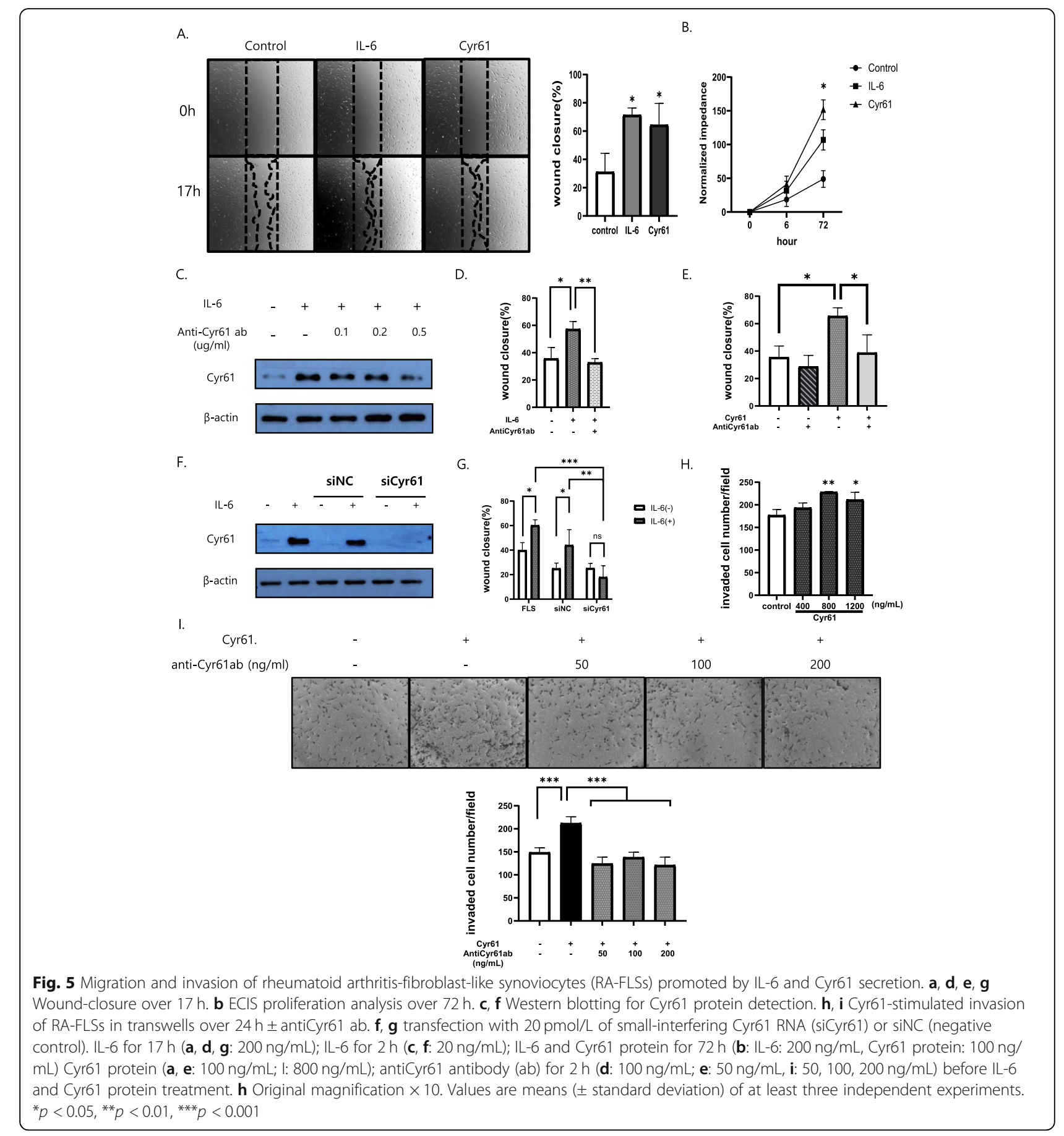

